\title{
PERCEPTIONS OF CONTINUING MEDICAL EDUCATION PARTICIPANTS REGARDING IMPROVEMENT OF PATIENT CARE THROUGH CONTINUING MEDICAL EDUCATION ACTIVITIES IN LAHORE DISTRICT
}

\author{
Shazia Tufail, Junaid Sarfraz Khan*, Shehla Baqai, Nilofer Mustafa \\ CMH Lahore Medical College, Lahore/National University of Medical Sciences (NUMS) Pakistan, *National University of Medical Sciences (NUMS) \\ Rawalpindi Pakistan
}

\begin{abstract}
Objective: To explore the perceptions of Continuing Medical Education participants about the improvement of patient care through Continuing Medical Education activities and to explore the factors hampering or favouring improvement of patient care through Continuing Medical Education activities.

Study Design: Qualitative phenomenological study.

Place and Duration of Study: University of Health Sciences, Lahore, from Dec 2016 to May 2017.

Methodology: In qualitative phenomenological study conducted at University of Health Sciences, Lahore from Dec 2016 to May 2017, semi structured in-depth interviews were conducted individually from 10 General Practitioners which were audiorecorded and transcribed. Code labels were assigned manually and grouped together into broader themes. Interpretation of themes was done after thematic analysis.

Results: Two participants were female and ten were male with experience ranging between 20-38 years. Three main themes with sub-themes were identified: (1) positive talk (Affirming the link between Continuing Medical Education and improved patient care), (2) negative talk (perceived hindrances in gaining full benefit from Continuing Medical Education activities), (3) concerns regarding current Continuing Medical Education activities.

Conclusion: Participants were found inclined towards Continuing Medical Education activities and felt more confident and comfortable in managing their patients. However, they felt that physicians working in rural areas were dealing directly with all sorts of patients and were more in need of targeted and tailored Continuing Medical Education activities.
\end{abstract}

Keywords: Attitude of health personnel, continuing medical education, patient care.

This is an Open Access article distributed under the terms of the Creative Commons Attribution License (https://creativecommons.org/licenses/by-nc/4.0/), which permits unrestricted use, distribution, and reproduction in any medium, provided the original work is properly cited.

\section{INTRODUCTION}

The concept of CME is probably as old as the start of medical practice itself. This can serve as a tool for not only helping in updating and polishing a doctor's skills to improve patient care but also to gain and augment the trust of the public in the medical/dental profession ${ }^{1}$.

Varied instructional methods have been used for conducting CME activities including longitudinal, interactive, case-and problem-based and patient-centric educational delivery models. The needs assessment of the learners for the CME activities can be carried out both by formal and informal needs assessment methods ${ }^{2}$.

Multiple qualitative studies have been conducted in order to explore this multi-dimensional phenomenon. Different aspects of CME have been studied including the views about the quality of programs ${ }^{3}$, barriers perceived ${ }^{4}$, and effectiveness of CME programs ${ }^{5}$. Most of the research was based on the assumption that

Correspondence: Dr Shazia Tufail, 40-C, Askari-1, Sarfraz Rafiqui Road, Lahore Cantt Pakistan

Received: 23 Feb 2020; revised received: 14 Jul 2020; accepted: 23 Jul 2020 the CME activities directly improve the healthcare practices of the physician which in turn improve the health outcomes for the patients, including the improvement in patient care ${ }^{6,7}$. Some of the identified barriers regarding CME included insufficient interaction with the speakers, unreal or abstract CME activities and unplanned CME programs started without prior needs assessment of the General Practitioners (GPs), specialists or the primary care physicians working in the rural areas.

Increased awareness about the CME was observed in Pakistan after the mandatory requirements for renewal of registration were put forward by the Pakistan Medical and Dental Council (PMDC). There has been a marked increase in the number of such activities organized both by the educational institutions as well as by the multiple professional organizations ${ }^{8}$. Pharma industry is one of the greatest sponsors for such activities?.

The conduction of CME activities requires substantial amount of financial and human resources. The effectiveness of the CME program in our own local context, is an area that requires extensive research. The 
primary objective of the study was to explore the perceptions of CME participants about the improvement of patient care through CME activities while the secondary objective was to explore the factors hampering or favouring improvement of patient care through CME activities. The study was conducted with the aim that it would help in identifying the key issues of our current CME programs.

In order to explore the CME activities and their effect on patient care, a literature search of the past 10 years was done. The main purpose of literature review was to establish the theoretical framework for the study while identifying the key terminology and the relevant studies and models supporting the topic. For this purpose, 69 key terms were phrased in consultation with the supervisor. The databases explored on the basis of these key terms included American Chemical Society, Cambridge University Press (CUP), ebrary, Science Online, Springer Link, Taylor \& Francis Journals, WILEY Online Library, OvidSP, Mc Graw-Hill's Access Medicine, McGraw-Hill's Access Science and Project Muse. The literature search yielded 222 results. They were then scrutinized through the titles and relevant abstracts were selected. Out of 110 abstracts were studied out of which 98 articles were selected. These 98 full text articles were then studied for literature review.

\section{METHODOLOGY}

This study was carried out at University of Health Sciences, Lahore, from from Dec 2016 to May 2017. GPs who attended the live events CME activities conducted by the UHS during 2016 were included in the study. It was started after the approval by the Ethical Review Committee for medical and biomedical research, University of Health Sciences.

Lists of accredited CME activities in 2016 inclu- ding the names and contact numbers of participants were obtained from the UHS. Twelve GPs meeting the inclusion criteria were initially registered through purposive sampling and written informed consent was obtained.

Semi structured in-depth interviews were conducted individually based on a set of 6 pre-determined open-ended questions, including the core question and associated questions related to the central issue ${ }^{10}$. The set of questions had been formulated based on review of literature followed by piloting them on a group of 5 experts. However, some questions were added based on the dialogues during the interviews whenever there was need for clarification. Interview Protocol was used for recording notes ${ }^{11}$. All interviews were audiorecorded and then transcribed. While transcribing, a verbatim account of all verbal and non-verbal utterances was developed. The participants were given pseudonyms to ensure anonymity. The transcribed interviews were then emailed to participants who were requested to check the accuracy and make any corrections if needed. Data collection was stopped after 10 interviews as the point of data saturation had reached and no new themes were found to be emerging. Data analysis was done concurrently with data collection. After repeated reading through the database, code labels were assigned manually to identified text segments. The codes were grouped together into broader themes serving as the key findings. An initial thematic map (fig-1) was developed based on the relationship of the various codes and themes. After further reading of the collated extracts for each theme, the themes were refined to form a final thematic map (fig-2). A demographic table was developed for the description of participants' characteristics. Detailed discussion and interpretation of the themes was done after thematic

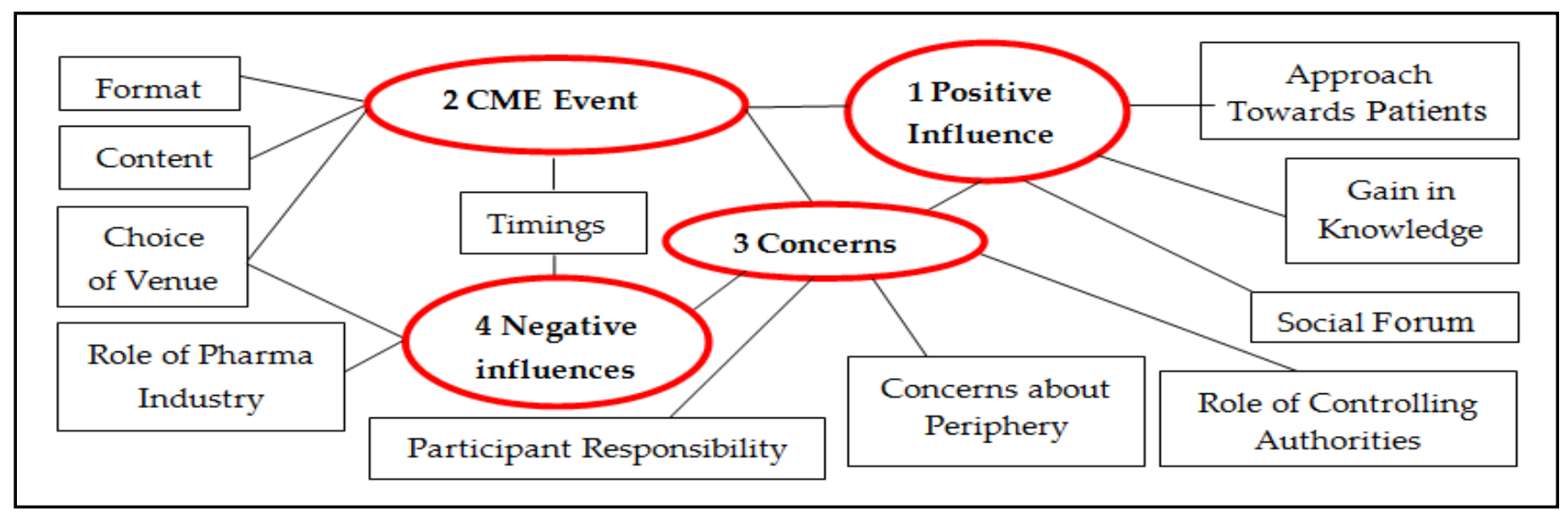

Figure-1: Initial thematic map developed with 4 main themes. 


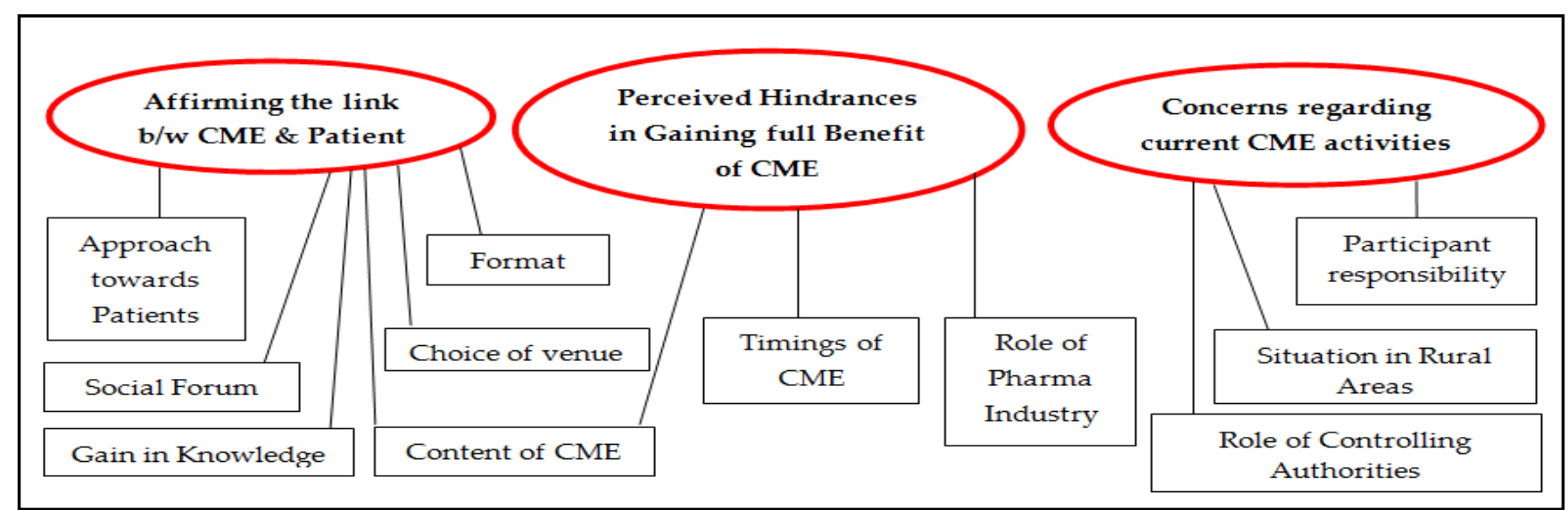

Figure-II: Final thematic map developed with 3 main themes.

analysis. Triangulation was done throughout data collection and analysis ${ }^{11}$.

\section{Qualitative Approach}

We employed a qualitative phenomenological research methodology to gain insight into the improvement of patient care through CME activities viewing $\mathrm{CME}$ as the central phenomenon requiring exploration and understanding ${ }^{12}$. The method used was the collective case study as used by multiple researchers and has been found to provide better comprehension and powerful explanation of a phenomenon ${ }^{13}$.

We worked within an experiential framework treating peoples' talks of experiences as a transparent window on their world ${ }^{14}$. Thematic analysis was chosen as the main method of analysis because of its accessible and theoretically flexible approach ${ }^{12}$, and was based on realist paradigm ${ }^{15}$. We have interpreted the experiences of the participants and meanings of the interviews in a straightforward way, assuming a simple, unidirectional relationship between meaning and experience and language ${ }^{16}$. We have followed an inductive approach keeping the research question as main focus. We have identified the themes at semantic level. Data was first organized to show patterns (description) and then attempted to theorize the patterns and their meanings and implications (interpretation) in relation to the previous literature ${ }^{16}$.

\section{Confirmability}

Methods of member checking, respondent validation and investigator triangulation were used to ensure the credibility of the findings ${ }^{19}$. To secure member checking, participants were asked to comment on the accuracy of verbatim transcribe of the interviews. Approval to use the direct personal quotes in written or verbal reports of the study was also obtained. Through respondent validation, a summary of findings was presented by email, asking them if they agreed to the perspectives represented in the reported findings. Investigator triangulation of the data was done by involving the co-researchers throughout data collection and analysis. Each process of the research was written in detail in order to ensure the dependability of the study.

\section{RESULTS}

Two participants were female and eight were male. Their ages ranged between 52-62 years, mean age of participants being $56.9 \pm 3.57$. All participants are currently practicing within Lahore District. The experience ranged between 20-38 years averaging 31.2 years (table-I).

\section{1-Themes}

Three main themes were identified as affecting the participants' perceptions: 1-Affirming the link between Continuing Medical Education and improved patient care: Six sub-themes were recognized (table-II). All of the participants had graduated $>25$ years ago and felt that CME could act as a bridge to fill in the gap making them confident in their practice. Interestingly, one participant felt that the doctors are now compelled to update their knowledge and change their approach in response to patient awareness. Live event CME activities that were conducted at a comfortable, easily accessible place were identified to enhance improvement in patient care through effective gain of knowledge and a positive change in the approach of doctors towards their patients. CME was recognized as a good social platform for peer-learning by sharing the experiences of the GP community and discussing the problems and their solutions. 
2-Perceived hindrances in gaining full benefit from Continuing Medical Education:

Three subthemes were recognized (table-III). A number of participants expressed their reservations about the various venues and timings of current $\mathrm{CME}$ participants voiced their concern about the prevailing situation of the lack of any well organized CME activities for doctors working in periphery. Participants felt that PMDC should control the different aspects of the CME activities comprehensively.

Table-I: Demographic characteristics of the participants*.

\begin{tabular}{c|c|c|c|c|c}
\hline S. No & Name & Gender & Age (Years) & $\begin{array}{c}\text { Work Experience } \\
\text { (Years) }\end{array}$ & Place of Work \\
\hline 1 & Dr. Ali & Male & 58 & 38 & Public \\
\hline 2 & Dr. Sadia & Female & 62 & 26 & Public \\
\hline 3 & Dr. Ahsan & Male & 53 & 32 & Private \\
\hline 4 & Dr. Anwer & Male & 58 & 35 & Private \\
\hline 5 & Dr. Sajid & Male & 59 & 35 & Private \\
\hline 6 & Dr. Suhail & Male & 60 & 25 & Private \\
\hline 7 & Dr. Amna & Female & 60 & 28 & Public \\
\hline 8 & Dr. Faisal & Male & 52 & 35 & Public \\
\hline 9 & Dr. Tayyab & Male & 54 & 20 & Private \\
\hline 10 & Dr. Abdullah & Male & 53 & & Private \\
\hline
\end{tabular}

${ }^{*}$ Participants were all General Practitioners and given pseudonyms

Table-II: Selected quotes of participants regarding theme-1.

\begin{tabular}{|c|c|c|}
\hline \multicolumn{3}{|c|}{ Theme 1: Affirming the link between Continuing Medical Education and improved patient care } \\
\hline S.No & Sub-theme & Quotes \\
\hline 1 & $\begin{array}{l}\text { Gain in } \\
\text { knowledge }\end{array}$ & $\begin{array}{l}\text { "It's like (pause) I have } 35 \text { years experience (pause) if the knowledge is not refreshed its one } \\
\text { year practice repeated } 35 \text { times. So to me it helps in getting the latest knowledge about the } \\
\text { new treatment regimens and practices." (Dr. Tayyab) }\end{array}$ \\
\hline 2 & $\begin{array}{l}\text { Approach } \\
\text { towards patients }\end{array}$ & $\begin{array}{l}\text { "It directly affects the approach of the attending physician. His horizon improves because of } \\
\text { the latest knowledge gained during these activities." (Dr. Sajid) }\end{array}$ \\
\hline 3 & Social forum & $\begin{array}{l}\text { "In addition to the clinical aspect of CME, there is a social aspect as well. The GP community } \\
\text { gets to gather at a platform and share their experiences with each other." (Dr. Tayyab) }\end{array}$ \\
\hline 4 & Format & $\begin{array}{l}\text { "The most important thing is you have an experienced person in front of you and you can } \\
\text { easily clear your queries. This is not possible in web-based activities as we cannot ask from } \\
\text { the computer directly." (Dr. Suhail) }\end{array}$ \\
\hline 5 & Venue & $\begin{array}{l}\text { "If CME activity is done in a central place where it is easily accessible for them, I think more } \\
\text { doctors would attend. The activities should be close to their workplace or somewhere it } \\
\text { would help them more." (Dr. Ali) }\end{array}$ \\
\hline 6 & $\begin{array}{l}\text { Content of CME } \\
\text { activities }\end{array}$ & $\begin{array}{l}\text { "There is a lack of talks in CME activities on ethics in medicine. This is the basis of medicine } \\
\text { but has been neglected in education and CME alike." (Dr. Sajid) } \\
\text { "Varied topics are discussed like those of medicine, surgery, radiology, psychiatry etc. which } \\
\text { can be discussed in specialties as well. I think they are proving to be very beneficial for the } \\
\text { GPs and more common problems and latest knowledge should be shared through these } \\
\text { interactive activities." (Dr. Abdullah) }\end{array}$ \\
\hline
\end{tabular}

activities. Varied opinions were found as to whether the morning or the afternoon sessions should be preferred. Only two participants supported the pharma companies and approved their efforts in promoting CME.

\section{3-Concerns regarding current Continuing Medical Education activities:}

Three subthemes were identified (table-IV). Several participants considered the non-serious attitude of the participants (just fulfilling the regulatory requirement) to be adversely affecting the CME activities. The

\section{DISCUSSION}

Through an examination of the perceptions of the CME participants, the study revealed insights into the critical role of $\mathrm{CME}$ in improving the patient care. All participants acknowledged a positive association of CME activities with improvement in patient care comparable to contemporary studies by Brown and Mansouri ${ }^{17,18}$. However, our results are contrasting with a survey aimed to investigate German ambulatory physicians' opinions about mandatory CME19. Although $73 \%$ of the 511 participants in that survey felt that CME 
helped them improve their medical knowledge, however, unlike our study, only half believed it improved patient care. Another qualitative study conducted in Iran also revealed that doctors did not believe it imp- rast, Shirazi et al20, argue that dissatisfaction can dissipate among GPs if needs are not addressed by special programs designed for them.

Table-III: Selected quotes of participants regarding theme-2.

Theme 2: Perceived hindrances in gaining full benefit from Continuing Medical Education

\begin{tabular}{|c|c|c|}
\hline S.No & Sub-theme & Quotes \\
\hline 1 & Choice of venue & $\begin{array}{l}\text { "CME programs carried out in very far off venues do not attract many participants. The } \\
\text { number of venues should be increased further so the participants do not have the feeling of } \\
\text { wasting too much time by going to far off places. It should be closer to one's workplace." (Dr. } \\
\text { Amna) } \\
\text { "Sometimes, at some places we are made to sit on benches which proves to be very difficult for } \\
\text { the participants at this age. When we were young, we could sit on benches (pause) But now I } \\
\text { am overweight and it is very difficult for me to sit there for long." (Dr. Anwer) }\end{array}$ \\
\hline 2 & Timings of CME & $\begin{array}{l}\text { "I have to do my practice in the morning (pause), afternoon suits me as I am relatively free." } \\
\text { (Dr. Ahsan) } \\
\text { "I am too tired in the afternoon after morning practice. It's better if the activiyies are planned } \\
\text { in the morning." (Dr. Ali) }\end{array}$ \\
\hline 3 & $\begin{array}{l}\text { Role of pharma } \\
\text { companies }\end{array}$ & $\begin{array}{l}\text { "The pharma companies are currently a big sponsor for these activities and obviously they } \\
\text { would want something in return. They are doing it for their own gains in the form of profit } \\
\text { from marketed drugs promoted during these activities." (Dr. Faisal) } \\
\text { "If the pharma companies do not contribute, these activities will die down as they are the } \\
\text { greatest supporters at good venues. The participants are not willing to spend a single penny." } \\
\text { (Dr. Sadia) }\end{array}$ \\
\hline & & f participants regarding theme-3. \\
\hline \multicolumn{3}{|c|}{ Theme 3: Concerns regarding current Continuing Medical Education activities } \\
\hline S.No & Sub-theme & Quotes \\
\hline 1 & $\begin{array}{l}\text { Participant } \\
\text { responsibility }\end{array}$ & $\begin{array}{l}\text { "I think that people are now considering it as a compulsion only for the PMDC registration } \\
\text { renewal which is a very wrong practice. They should realize the importance of CME." (Dr. } \\
\text { Tayyab) } \\
\text { "But you cannot make anyone learn by force. If the participants are only interested in } \\
\text { marking the attendance to gain credit hours and eat the lunch, they usually sleep throughout } \\
\text { the activity. So how can the patient care improve through such doctors even if they are } \\
\text { attending CME activities?" (Dr. Abdullah) }\end{array}$ \\
\hline 2 & $\begin{array}{l}\text { Situation in } \\
\text { periphery }\end{array}$ & $\begin{array}{l}\text { "There should be some arrangement of collecting 10-15 doctors on the district level and then } \\
\text { CME should be arranged at the THQ, DHQ or RHC level. They are directly dealing with the } \\
\text { public and our major portion of population is in villages so I think arranging CME programs } \\
\text { for them will directly affect patient care." (Dr. Suhail) }\end{array}$ \\
\hline 3 & $\begin{array}{l}\text { Role of controlling } \\
\text { authorities }\end{array}$ & $\begin{array}{l}\text { "The CME activities should be controlled by a central authority like PMDC which should lay } \\
\text { down proper parameters and SOPs for the CME activities." (Dr. Sadia) }\end{array}$ \\
\hline
\end{tabular}

roved patient care ${ }^{4}$. The high positive perceptions seen in our study could be due to the fact that our study included only GPs, most of them without any postgraduate qualification. They relied mostly on current CME activities for updating their knowledge. Gaining the updates in management of common diseases was therefore probably perceived as improvement in patient care. This is also supported by the fact that although all of them were GPs, and the facilitators of most of the CME programs they had attended were specialists, they had no objections. Rather, they seemed keen to gain from the experiences of the consultants. In cont-
The participants showed serious concern about the learning environment of the CME activities. A study by Harris et al reviews plans to implement information technology for newly designed $\mathrm{CME}$ programs ${ }^{21}$, while the local CME participants are still forced to sit on "benches" or in "small lecture rooms in basements", where the basic facilities of multimedia and white boards are often lacking.

The apparent lack of interest by some physicians attending the CME programs was also perceived to be partly due to the facilitators' lack of communication and inattention to the audience. The major factors inv- 
olved in the effectiveness of any CME program include both the interaction and applicability ${ }^{20}$. The same experience has been shared by a study carried out in Iran $^{4}$ where insufficient interaction between the facilitators and trainees was identified as one of the major barriers influencing the effectiveness of CME programs.

In this study, the participants identified the need for planning and designing effective CME activities. Similar results where improvement of available needs assessment modalities in order to develop CME curricula for different specialties has been recognized were obtained by Dionyssopoulos 5 . A study by Spivey similarly provided evidence in favor of specially designed, learner-centered educational events with a safe and supportive, friendly context to gain maximum effectiveness from CME activities 22 .

Another major area of concern unveiled by the study was the role of pharmaceutical companies in organizing and conducting CME activities. The participants doubted the sincerity behind this sponsorship. These findings of the study are in line with the findings of a study by Miyata ${ }^{23}$, reviewing CME as a globally thriving enterprise. Contemporary studies by Greenberg and Kawczak have also shown that the aim of the funding is to change the prescribing behavior of the physicians and may affect topic selection or the time devoted to specific topics in order to achieve desired results ${ }^{24,25}$. However, it was acknowledged that financial support was unavoidable in our set-up due to the lack of appropriate funding and facilities by the controlling authorities and the educational institutions for fruitful, targeted activities. Like our study, Shnier has recognized that future of CME activities depends on the funding by the pharma industry ${ }^{26}$. Guidelines need not only to be developed but implemented as well to balance the influence of the industry. Although documented ruling of PMDC exists refusing accreditation of CME activities solely organized for commercial benefit of the "Big pharma" 27, but the question is: Who has seen to its application?.

The study reflected that participants seemed to be disappointed with the role the main controlling authority i.e., PMDC is currently playing in relation to the CME activities. This was considered particularly in relation to the physicians working in rural areas who face more difficulties in accessing and attending the CME activities in contrast to their urban colleagues. Stewart ${ }^{28}$, examined a similar situation in his study. Research has shown that CME needs for rural physi- cians are also different as they may have to provide services catered by hospitals in urban settings. Two thirds of our population resides in rural areas. Optimal learning facilities in the form of innovative methods of CME delivery including procedural skills need to be devised in order to improve the patient care.

Another important role of CME identified during the study was the social interactions among the participants which facilitated peer learning. Although it is not identified as an educational goal for the CME, yet adequate attention given to this social aspect of $\mathrm{CME}$ may help in improving performance outcomes and patient care in the long run.

\section{ACKNOWLEDGEMENT}

Contribution of general practitioners and my seniors who guided and supported me is highly appreciated.

\section{Disclosure}

This study was carried out as part of thesis requirement of Masters in Health Professions degree from UHS.

\section{LIMITATION OF STUDY}

Although accepted qualitative research methods have been used for this study, the transferability of the findings may be influenced by certain limitations including small sample size and single source of data. Exploring the situation in other provinces of Pakistan and using multiple data sources like observations, documents or questionnaires etc. may enhance the understanding of the issue. To have the full insight into this complex phenomenon, exploration should be done of the perceptions of specialists as well.

To our knowledge, this is the first qualitative study carried out on this topic in our local context. Hence, comparison of the results was not possible with any other local study. Therefore, further studies on a broader scale are suggested to ascertain whether or not the present findings can be endorsed.

\section{CONCLUSION}

This study is a small endeavor towards the exploration of the perceptions of CME participants in order to gain some insight of this complex multifaceted phenomenon. It is reassuring to note that the physicians in Pakistan have started realizing the true meaning and importance of CME. It is, however, imperative that PMDC recognize the need for reforms in CME and get actively engaged for achieving those. The most important is the need to link CME to a change in physician behavior in order to achieve outcomes. In 
addition, it is essential to develop needs assessment modalities in order to design updated curricula. Only when these reforms have been accomplished will we be finally able to view medical education as a continuum from undergraduate education through education of the practicing physician. Due to this life-long learning, patient care will be favorably impacted. Education will change from an episodic experience to a continuous process and one that is based on the realities of practice. These reforms will take time to accomplish and to be accepted by a profession that currently views itself as besieged by regulatory agencies and without the time and resources needed to comply with the changes.

\section{CONFLICT OF INTEREST}

This study has no conflict of interest to be declared by any author.

\section{REFERENCES}

1. Khan AW. Continuing Professional Development (CPD); What should we do?. Banglad J Med Educ 2012; 1(1): 37-44.

2. Vakani F. Performance improvement CME for quality: challenges inherent to the process. Int J Health Care Qual Assur 2015; 28(7): 746-50.

3. Amirnia M, Mohammadi F, Vahidi RG, Mohammadzadeh M, Gojazadeh M, Hejazi SA, et al. General practitioners' views toward quality of continuing medical education programs in tabriz. Iran J Med Educ 2012; 12(4): 231-9.

4. Faghihi SAA, Khankeh HR, Hosseini SJ, Soltani Arabshahi SK, Faghih Z, Parikh SV, et. al. Improving continuing medical education by enhancing interactivity: lessons from Iran. J Adv Med Educ Prof 2016; 4(2): 54-63.

5. Dionyssopoulos A, Karalis T, Panitsides EA. Continuing medical education revisited: theoretical assumptions and practical implications: a qualitative study. BMC Med Educ 2014; 14(2): 1051-54.

6. Goulet F, Hudon E, Gagnon R, Gauvin E, Lemire F, Arsenault I. Effects of continuing professional development on clinical performance: results of a study involving family practitioners in Quebec. Can Fam Physician 2013; 59(5): 518-25.

7. Filipe HP, Silva ED, Stulting AA, Golnik KC. Continuing professional development: Best practices. Middle East Afr J Ophthalmol 2014; 21(2): 134-38.

8. UHS and its affiliated institutions organize 1578 CME programmes from Jan-Oct 2015. Pulse Inter 2015; 12(1): 1-5.

9. Vakani FS, Jafri W, Amin A, Sheerani M. Continuing medical education and pharmaceutical industry. J Coll Physicians Surg Pak 2011; 21(6): 360-1.

10. Jamshed S. Qualitative research method-interviewing and observation. J Basic Clin Pharm 2014; 5(4): 87-8.

11. Creswell JW. Educational research, planning, conducting and evaluating quantitative and qualitative research. $4^{\text {th }}$ ed. Upper Saddle River, NJ: Pearson Education Inc; 2012 [Internet] Avail- able from: https://www.academia.edu/3262007/Educational _research_Planning_conducting_and_evaluating_quantitative_ and?bulkDownload=thisPaper-topRelated-sameAuthor-citing This-citedByThis-secondOrderCitations\&from $=$ cover _page.

12. Braun V, Clarke V. Using thematic analysis in psychology. Qual Res Psychol 2006; 3(2): 77-1.

13. Brantlinger E, Jimenez R, Klingner J, Richardson V. Qualitative studies in special education. J Except Child 2005; 71(2): 195-7.

14. Hollway W, Jefferson T. Doing qualitative research differently: free association, narrative and the interview method. London: Sage; 2000 [Internet] Available at: http://oro.open.ac.uk/ 15410/1/H\&J4FANImeth08.pdf.

15. McLeod J. Qualitative research in counselling and psychotherapy. London: Sage; 2001 [Internet] Available at: https:// methods.sagepub.com/book/qualitative-research-incounselling-and-psychotherapy.

16. Sandelowski M. Using qualitative research. Qual Health Res. 2004; 14(10): 1366-86.

17. Brown JA, Beaser RS, Neighbours J, Shuman J. The integrated Joslin performance improvement/CME program: A new paradigm for better diabetes care. J Contin Educ Health Prof 2011; 31(1): 57-63.

18. Mansouri M. A meta-analysis of continuing medical education effectiveness. J Contin Educ Health Prof 2007; 27(1): 6-15.

19. Kempkens D, Dieterle WE, Butzlaff M, Wilson A, Bocken J, Wilm $\mathrm{S}$, et. al. German ambulatory care physicians' perspectives on continuing medical education-a national survey. J Contin Educ Health Prof 2009; 29(4): 259-8.

20. Shirazi M, Parikh SV, Dadgaran I, Silén C. Designing Effective CME-potential barriers to practice change in the management of depression: A qualitative study. Psych 2013; 4(1): 25-28.

21. Harris JM, Sklar BM, Amend RW, Novalis-Marine C. The growth, characteristics, and future of online CME. J Contin Educ Health Prof 2010; 30(1): 3-10.

22. Spivey BE. Continuing medical education in the United States: Why it needs reform and how we propose to accomplish it. J Contin Educ Health Prof 2005; 25(3): 134-43.

23. Miyata Y. Conflict of interest regarding clinical physicians relationship with pharmaceutical industry and medical education. Seishin Shinkeigako Zasshi 2010; 112(11): 1136-45.

24. Greenberg RD. Conflicts of interest: can a physician serve two masters. Clin Dermatol 2012; 30(2): 160-73.

25. Kawczak S, Carey W, Lopez R, Jackman D. The effect of industry support on participants perceptions of bias in continuing medical education. Acad Med 2010; 85(1): 80-4.

26. Shnier A, Lexchin J. Continuing medical education and pharmaceutical industry involvement: an evaluation of policies adopted by Canadian professional medical associations. Int J Risk Saf Med 2017; 29(1-2): 1-16.

27. Tabish A. A review of PM \& DC guidelines for continuing medical education. Medical News 2015 [Internet] Available at: https://www.medicalopedia.org/4840/a-review-of-pmdcguidelines-for-continuing-medical-education/

28. Stewart GD, Khadra MH. The continuing medical education activities and attitudes of Australian doctors working in different clinical specialties and practice locations. Aust Health Rev 2009; 33(1): 47-56. 